\title{
Sobre a vulnerabilidade da designação rígida: a crítica kuhniana à Teoria Causal da Referência
}

\author{
On the vulnerability of rigid designation: the \\ kuhnian criticism of the Causal Theory of Reference
}

\section{Rodrigo Sabadin Ferreira}

Doutorando em filosofia na UFRGS

Resumo $^{41}$ : A aplicação da Teoria Causal da referência à termos de espécies naturais é geralmente defendida com base em argumentos que pressupõem a legitimidade de experimentos mentais como o famoso 'Experimento da Terra Gêmea'. Essa espécie de argumento pressupõe que: (i) é possível distinguir entre propriedades acidentais e essenciais de espécies naturais e (ii) há um mundo no qual espécies naturais distintas partilham todas as suas propriedades acidentais, mas diferem em alguma propriedade essencial. Esse texto tem por objetivo defender uma interpretação da crítica de Thomas Kuhn à Teoria Causal baseada na recusa parcial de (i) e (ii) a partir da interpretação taxonômica de Ian Hacking da tese de incomensurabilidade entre teorias científicas. Nossa conclusão é que tal leitura permite recusar a

\footnotetext{
$41 \quad$ Agradeço aos avaliadores deste texto pelas sugestões que contribuíram para seu melhoramento, bem como aos professores Paulo Faria, Jônadas Techio e, especialmente Eros Moreira de Carvalho por suas críticas e sugestões. Agradeço também ao meu colega e amigo Jeferson Huffermann por ter me incentivado a submeter este texto para publicação.
} 
recorrente afirmação encontrada na literatura de que a Teoria Causal refuta a tese de incomensurabilidade Kuhniana.

Palavras-chave: Thomas Kuhn; Mundos Possíveis; Incomensurabilidade; Espécies Naturais; Teoria Causal da Referência;

Abstract: The application of the Causal Theory of Reference to terms for natural kinds is generally defended on the basis of arguments which presuppose the legitimacy of mental experiments like the famous 'Twin Earth Experiment'. This kind of argument presuppose that: (i) it is possible to distinguish accidental from essential properties of natural kinds and (ii) that there is a world in which distinct natural kinds share all essential properties, but differ in their essential properties. This text aims at defending an interpretation of Thomas Kuhn's criticism of the Causal Theory based on the partial refusal of (i) and (ii) that builds upon Ian Hacking's taxonomic reading of the thesis of incommensurability thesis between scientific theories. Our conclusion is that such a reading allows one to refuse the recurrent claim that the Causal Theory refutes the Kuhnian thesis of incommensurability.

Key-words: Thomas Kuhn; Possible Worlds; Incommensurability; Natural kinds; Causal Theory of Reference;

$\mathbf{H}$ ilary Putnam e Saul Kripke desenvolveram, paralelamente, ideias que ficaram conhecidas como "externalismo semântico" ou "teoria causal da referência". Em primeiro momento, essa foi aplicada para nomes próprios por Kripke em Naming and Necessity (KRIPKE, 1980), em seu argumento a favor da tese de que a referência de nomes logicamente próprios, como "Aristóteles" ou "Barack Obama", não é determinada por meio de uma descrição associada ao nome, mas por: (a) o fato do nome ter sido introduzido para referir apenas àquele indivíduo e nenhum outro e; $(b)$ o fato de que há uma cadeia histórico-causal que conecta aquele nome àquele indivíduo específico (KRIPKE, 1980, p.135) ${ }^{42}$.

$42 \quad$ Na terminologia técnica de Putnam e Kripke, nomes próprios e termos de espécies naturais "designam rigidamente". Nomes próprios como "Aristóteles" designam o mesmo indivíduo em qualquer mundo possível, a saber, o mesmo indivíduo que, no mundo atual, é designado pelo nome "Aristóteles". De maneira similar, termos de espécie como "água" e "planeta", supostamente, referem-se ao mesmo tipo de coisa em qualquer mundo possível. 
De maneira análoga à aplicação da teoria causal a nomes próprios, Kripke e, especialmente, Putnam, insistiram que a referência é a parte mais fundamental do significado de termos de espécies naturais como "planeta", "água" ou "elétron". Tal elaboração teórica é uma teoria "causal" da referência pois o que é fundamental para estabelecer o significado tanto de nomes quanto termos de espécies é a interação causal com certos tipos de entidades, de modo que a "posse de competência linguística conectada com o termo" (PUTNAM, 1975, p.198) não é suficiente para que o termo possa ser usado para referir. Assim, a tese central de Putnam e Kripke em relação a termos de espécie é que a referência desses é fixada inicialmente por um ato de "batismo" de uma amostra inicial do tipo natural em questão e, não, por meio de certa descrição ou conjunto de descrições que determinem a extensão do termo.

Putnam procura estabelecer isso por meio de um dos experimentos de pensamento mais famosos da história recente da Filosofia -conhecido como "experimento da Terra Gêmea". Apesar de ser muito bem conhecido, podemos descrever brevemente o experimento mental de Putnam. Ele pede que imaginemos um mundo possível em que existe um planeta, a Terra Gêmea, que é praticamente idêntico à Terra, com a única diferença de que, na Terra Gêmea, "água" não designa H20, mas um composto muito complexo que é idêntico à água em todas as suas propriedades exceto sua composição química, cuja fórmula é abreviada por XYZ (PUTNAM, 1975, p.223). No cenário

Putnam e Kripke formularam suas teorias da referência em oposição a teorias descritivistas. Tanto no que diz respeito a nomes próprios quanto termos de espécie, o locus classicus de uma teoria descritivista da referência é o artigo seminal de Frege Sobre Sentido e Referência (FREGE, 1948). No que diz respeito a termos de espécies naturais, o aspecto fundamental de tais teorias é que todos esses possuem uma intensão e uma extensão e a intensão determina a extensão. De modo geral, teorias descritivistas afirmam que a extensão de um termo como "água" é fixada por meio de uma certa descrição como "líquido inodoro, incolor que ferve a $100^{\circ} \mathrm{C}$ ". Desse modo, descritivistas defendem que a competência linguística com respeito ao uso de um termo de espécie consiste na capacidade de usar descrições corretamente para identificar seus referentes, de modo que a referência do termo "água" é fixada por meio de uma certa descrição ou conjunto de descrições que determinam a extensão do termo. 
imaginado por Putnam, a palavra "água" na Terra (ou "água-t") tem uma extensão diferente de "água" na Terra Gêmea (ou "água-tg"). Desse modo, se cientistas da Terra investigassem a substância que se parece com H20 - mas que é XYZ - da Terra Gêmea, eles chegariam à conclusão de que: (a) na Terra, o termo "água" significa H2O, ou seja, "água-t" significa H2O e; (b) na Terra Gêmea, o termo "água" significa XYZ, isto é, "água-tg" significa XYZ (PUTNAM, 1975, p.224), sendo que, claro, o que permite aos habitantes da Terra e da Terra Gêmea afirmar tais enunciados é seu conhecimento de química a partir do qual eles diferenciam $\mathrm{H} 2 \mathrm{O}$ de XYZ, isto é, água-t de água-tg.

Putnam pede, então, que imaginemos a Terra e a Terra Gêmea no ano 1750, quando a composição química da água ainda não era conhecida (em ambos os planetas). Se imaginarmos dois indivíduos nesse período, um na Terra Gêmea e outro na Terra, ambos terão as mesmas crenças sobre aquilo que em cada planeta é conhecido como "água": ambos reconheceriam "água" como sendo, por exemplo, aquela substância que mata a sede ou corre nos rios, e nenhum desses indivíduos teria conhecimento da composição química desses compostos. Assim, apesar de terem as mesmas crenças (e, portanto, descreverem aquilo que chamam por "água" do mesmo modo) eles utilizariam o mesmo termo para se referir a diferentes substâncias, a saber, H2O em um caso e XYZ no outro (PUTNAM, 1975, p.224). Com isso, Putnam pretende estabelecer que a única condição necessária e suficiente para a continuidade da referência é a existência de uma cadeia histórico causal que vincula o termo com uma determinada amostra do tipo de coisa que este foi introduzido para denotar (PUTNAM, 1975, p.225). Uma das principais consequências extraídas por Putnam da teoria causal da referência é a estabilidade da referência de boa parte dos termos teóricos ao longo do tempo. De acordo com os defensores da teoria causal, o que muda com uma revolução científica é apenas a intensão do falante, e o que é relevante para a prática (e sucesso) da ciência é a referência, que se mantém constante.

Como é bem sabido, Thomas Kuhn defendeu uma concepção do desenvolvimento histórico do conhecimento cientí- 
fico baseado em ciclos sucessivos de ciência normal, crises, revoluções e volta à ciência normal. Períodos em que a disciplina científica é guiada por um único paradigma de modo bem-sucedido são chamados períodos de ciência normal. O período de ciência normal é interrompido por eventuais crises suscitadas pelo surgimento de anomalias, isto é, problemas que o paradigma não é capaz de resolver. A persistência das anomalias e o surgimento de um novo paradigma levam à uma disputa cujo desfecho pode ser o abandono do antigo paradigma e o surgimento de um novo período de ciência normal. Fundamental para essa teoria é a tese de que teorias científicas são incomensuráveis. Tal como articulada nos escritos tardios ${ }^{43}$ de Kuhn, "incomensurabilidade" consiste numa relação entre teorias científicas tomadas como conjuntos de enunciados, tal que, duas teorias $\mathrm{T}$ e T* são incomensuráveis se, e somente se, há enunciados e/ou conceitos de $T^{*}$ que não podem ser expressos nos termos de $\mathrm{T}$, ou vice-versa. A tese de incomensurabilidade, portanto, é uma tese sobre tradução (KUHN, 2003, p.80). Dado que uma das consequências da tese de incomensurabilidade é a variação dos referentes dos termos científicos, os argumentos da teoria causal surgem como uma alternativa natural de resposta às ideias de Kuhn: ao tornar a referência uma constante ao longo da história da ciência e torná-la um meio de comparação - e tradução - de teorias, poderia se evitar completamente o problema da incomensurabilidade (HACKING, 2012, pp.154156). Desse modo, a teoria causal foi tomada como uma via direta de ataque à tese de Kuhn. Diante disso, nosso objetivo aqui é mostrar que essa estratégia é equivocada.

Para começar, há um ponto crucial a respeito do experimento de pensamento de Putnam que é largamente negligenciado na literatura: ele pressupõe que a teoria química atual é capaz de descrever verdadeiramente um mundo possível em que $\mathrm{H} 2 \mathrm{O}$ e XYZ (a "água"da "Terra Gêmea") existam e tenham as mesmas propriedades, exceto a composição química. Evidentemente, esse aspecto do experimento está longe de ser irrelevante: apenas assim é possível que, ao visitar a Terra Gêmea, os terráqueos descubram que aquela substância que possui as mesmas

$43 \quad$ Nossa discussão será focada nos textos de Kuhn dos anos noventa. 
propriedades substanciais de $\mathrm{H} 2 \mathrm{O}$ é, na verdade, XYZ. Sob raciocínio semelhante, há um argumento oferecido por Kuhn - largamente negligenciado na literatura - que procura estabelecer que um mundo no qual a Terra e a Terra Gêmea existam com suas respectivas "águas", H2O e XYZ, é, em um sentido que iremos esclarecer nesse texto, impossível. Mostraremos que as razões de Kuhn oferecidas para sustentar esse argumento possuem elementos para recusar parcialmente a aplicação da teoria causal à termos de espécies naturais, e que, assim, a teoria causal não refuta diretamente a teoria kuhniana ${ }^{44}$.

$*$

Kuhn compreende teorias científicas como léxicos estruturados constituídos pelos conceitos (KUHN, 2003, pp.116-7). Em sua versão madura, a tese de incomensurabilidade de Kuhn é uma consequência do modo como os significados dos conceitos teóricos que formam um léxico são fixados e, principalmente, aprendidos. $\mathrm{O}$ aspecto essencial da teoria Kuhniana de termos teóricos é que os léxicos de teorias devem ser compreendidos como estruturas taxonômicas de classificação formadas por termos de espécies [kinds]. Do ponto de vista sintático, o que caracteriza esses léxicos é que os termos que os formam são "[...] substantivos contáveis [count nouns] juntamente com os substantivos não-contáveis [mass nouns], palavras que se combinam com substantivos contáveis em expressões que admitem o artigo indefinido." (KUHN, 2003, p.117). Do ponto de vista semântico, a principal característica desses termos é o que Kuhn chama de "princípio da não-superposição" [no-overlap-principle]: termos de espécie que compõem o léxico de uma dada teoria não podem "superpor-se no que diz respeito a seus referentes, a menos que sejam relacionados como uma espécie [species] a um gênero"(KUHN, 2003, pp.117-118).

Teorias discriminam, a partir desse léxico, os objetos que constituem seu domínio de estudo em espécies [kinds]. Domi-

$44 \quad$ Kuhn explora o exemplo de Putnam, mas sua argumentação claramente tem um propósito geral, a saber, de que esses problemas que surgem ao se tomar o termo "água" como designando rigidamente podem surgir com qualquer termo científico. Para uma defesa similar, ver Sharrock e Read, 2002 . 
nar o significado de um termo de espécie não consiste necessariamente em conhecer definições, mas na capacidade de aplicar esses termos ou conceitos que compõem o léxico a instâncias corretas (mesmo que tacitamente) e na capacidade de formular enunciados sobre as instâncias desses termos que compõem o léxico. É desse modo que teorias diferentes permitem a formulação de certos enunciados e não permitem a formulação de outros. A impossibilidade de tradução é uma consequência de uma sobreposição dos referentes dos termos de um léxico que forma uma taxonomia. Se há uma divergência local nos léxicos de duas comunidades científicas, então, como afirma Kuhn:

Os membros de uma delas podem fazer (e ocasionalmente farão) enunciados que, embora plenamente significativos nessa comunidade de discurso, não podem, em princípio, ser articulados pelos membros da outra. (KUHN, 2003, p.118)

\section{De modo que:}

Transpor essa lacuna entre as comunidades iria requerer o acréscimo, em um dos léxicos, de um termo para espécies [kinds] que se intersecta, compartilha um referente com um termo já estabelecido. É essa situação que o princípio da não-superposição [no- overlap principle] exclui. A incomensurabilidade torna-se, assim, um tipo de intradutibilidade, circunscrita a uma ou outra área em que duas taxonomias lexicais diferem. (KUHN, 2003, p.118) ${ }^{45}$

Esse diagnóstico se deve ao modo como Kuhn compreende o aprendizado de termos teóricos. Desde a Estrutura das Revoluções Científicas (2012), Kuhn argumentou que o aprendizado de conceitos de uma teoria se dá por meio da solução de problemas [puzzles] de paradigmas. "Paradigmas", no sentido

$45 \quad$ Na taxonomia dos corpos celestes de Ptolomeu, por exemplo, planetas são uma espécie de corpo celeste. O conceito de planeta de Ptolomeu abarcava o Sol, a Lua, Marte, Júpiter, entre outros corpos celestes em sua extensão, sendo que a Terra, por exemplo, não era um planeta. Na transição para a astronomia copernicana, a Terra passou a ser classificada como um planeta, o Sol foi classificado como uma estrela e uma nova espécie foi introduzida no léxico: os satélites. Alguns dos conceitos do léxico que formam uma taxonomia não podem ser traduzidos nos termos da outra sem perda, dado que, esse determinado grupo de termos (não todos) tem seu significado definido holisticamente. 
específico de "exemplares" são "soluções de problemas aceitas pelo grupo como paradigmáticas" (KUHN, 2009, p.316); são "as realizações científicas universalmente reconhecidas que, durante algum tempo, fornecem problemas e soluções modelares para uma comunidade de praticantes de uma ciência." (KUHN, 2012, p.13).

Segundo Kuhn, o aprendizado de teorias se dá através da exposição dos estudantes à casos paradigmáticos de problemas e solução de problemas. Os cientistas, ao se depararem com problemas ou quebra-cabeças, resolvem-nos a partir de um raciocínio por analogia - problemas novos são assimilados a problemas paradigmáticos já resolvidos, para que, desse modo, as soluções encontradas a problemas já resolvidos sirvam de modelo para solucionar novos problemas. Um exemplo que pode ser explorado é o das aplicações da segunda lei de Newton. A generalização simbólica $\mathrm{F}=m$. $a$ é um método de solução exemplar para uma série de quebra-cabeças envolvendo a movimentação de corpos através do espaço. No entanto, quando aplicada dessa maneira, apenas $\mathrm{F}=m . a$, a generalização não trata com o mesmo sucesso toda e qualquer situação em que corpos se encontram em movimento, sendo necessária alguma modificação na aplicação da lei. Um desses casos é o problema da queda livre, em que $\mathrm{F}=\mathrm{m}$. a se torna $m \cdot g=m \mathrm{~d}^{2} \mathrm{~s}$ / $\mathrm{d} t^{2}$ (KUHN, 1977, p.299).

De acordo com Kuhn, ao aprender a aplicar generalizações simbólicas como $\mathrm{F}=m \cdot a$ em demonstrações matemáticas aplicadas em situações concretas, o aprendiz está adquirido duas habilidades: 1) como aplicar conjuntamente os termos " $\mathrm{F}$ ", " $m$ ", " $a$ " a eventos e propriedades de objetos e; 2) como outras generalizações simbólicas podem ser derivadas de $\mathrm{F}=m \cdot a$ a partir das relações de semelhança entre as diferentes situações de aplicação. Ao aplicar exemplares na solução de problemas, o aprendiz está sendo treinado para reconhecer novos problemas como os problemas que os exemplares já resolvem. Em outras palavras, o estudante aprende a pensar em novos problemas de maneira análoga àqueles para os quais o exemplar já possui uma aplicação bem estabelecida (KUHN, 2012, p. 188). Esse 
aprendizado, portanto, introduz o vocabulário da teoria em questão apresentando situações concretas do uso desse vocabulário (KUHN, 2003, p.87).

É importante notar que esse processo de aprendizado a partir da solução de problemas com base em casos particulares paradigmáticos não é o mesmo que aprender a seguir uma regra com condições necessárias e suficientes de aplicação. Ao aprender e proceder dessa maneira, através dos exemplares, o que o cientista está adquirindo e empregando é a capacidade de reconhecer padrões de similaridade e dissimilaridade entre diferentes objetos, fenômenos e situações (KUHN, 2012, pp. 188-189). Em outras palavras, diferentemente de processo algorítmico no qual uma regra é seguida, esse raciocínio baseado em casos paradigmáticos não é necessariamente redutível a uma generalização ou regra explícita em termos de condições necessárias e suficientes, seja para a adequação de uma solução, ou aplicação de um conceito a um objeto.

$\mathrm{O}$ aspecto mais fundamental de uma revolução científica é a substituição de um ou mais de um exemplar que deixou de ser eficiente na solução de problemas por outro. Para Kuhn (2012), os exemplares são a principal ferramenta de que os cientistas dispõem para relacionar a natureza às suas teorias. Do mesmo modo, exemplares cumprem o papel de relacionar conceitos, como no já mencionado caso da segunda lei de Newton, em que a generalização $\mathrm{F}=m$. $a$ instancia a relação que conceitos como "massa", "força" e "aceleração" mantêm entre si. Esses conceitos teóricos adquirem seu significado de maneira holística. Boa parte dos conceitos científicos só possuem significado quando relacionados uns com os outros, sendo impossível aprendê-los isoladamente. O papel dos exemplares é fazer com que esses conceitos como "massa", "força" e "aceleração" sejam aprendidos conjuntamente, através da sua aplicação na solução de problemas ou na sua exposição ostensiva em situações concretas (KUHN, 2012, p.46-47). Desse modo, o que explica a mudança de significado dos termos teóricos na transição de teorias e a incomensurabilidade entre teorias é uma divergência entre os paradigmas compreendidos como conjunto de 
exemplares, que são utilizados enquanto ferramenta de ensino de padrões de reconhecimento de relações de similaridade e dissimilaridade na prática de solução de problemas. Conceitos como "massa", "força", "tempo", "aceleração", são aprendidos e adquirem seus significados no interior de uma teoria a partir da aplicação dos exemplares na resolução de problemas ou quebra-cabeças. O que ocorre no processo de uma revolução científica é a substituição de um paradigma (exemplar) por outro com ele incompatível - isto é, por outro paradigma que determina relações de similaridade de problemas e soluções diferentes de seu antecessor. Como teorias sucessivas diferentes possuem exemplares diferentes que relacionam conceitos à natureza de maneira diferente, alguns de seus enunciados podem, e frequentemente são, impossíveis de serem traduzidos.

Buscando uma explicação mais detalhada das características dessas taxonomias lexicais e como elas dão origem à impossibilidade (localizada) de tradução, Ian Hacking (HACKING, 1993) extraiu das considerações de Kuhn três condições que um termo deve satisfazer para ser considerado um termo lexical ou de espécies naturais/científicas. Como veremos, ele faz ressalvas acerca dessas condições e sobre os tipos de termos a que elas se aplicam, que serão relevantes para o restante da discussão. As três condições são as seguintes:

1. Tipos científicos são taxonômicos. As relações entre tipos que criam a taxonômica são lógicas, conceituais ou lexicais. Essa condição se refere apenas a[sic] tipos em qualquer ramo da ciência com um paradigma. 2. Tipos científicos taxonômicos possuem infima species. Há apenas um número finito de palavras e descrições em uso em qualquer ramo da ciência. Assim, um arranjo taxonômico de nomes para tipos científicos será sempre esgotado por exaustão. Para ser interessante, essa afirmação deve ser mais sutil, de que há tipos tais que, como pressuposição da ciência, não podem ter subdivisões que possa contar como tipos científicos. 3. Tipos científicos são projetáveis. Nomes para tipos científicos são projetáveis na linguagem da comunidade científica que os emprega. Os nomes são usados na realização de generalizações, formação de expectativas a respeito do futuro (ou eventos não examinados do passado ou presente distante). Eles podem ser utilizados em condicionais contrafactuais. Eles ocorrem em sentenças que possuem o caráter de leis [lawlike sentences] (HACKING, 1993, p.293. Tradução nossa.) 
A condição 1 afirma que, para um termo fazer parte de um léxico teórico, ele precisa estar relacionado à estrutura lexical da teoria da qual ele faz parte, seja como um termo de espécie que se subdivide em subespécies, ou como um termo de subespécie subordinado a outra espécie de ordem superior. A condição 2 afirma que há espécies não subdivisíveis. A condição 3 afirma que, se um termo de espécie faz parte de um léxico teórico, deve ser possível para um membro da comunidade científica utilizar aquele termo para fazer projeções.

Nesses termos, a impossibilidade de tradução pode ser caracterizada a partir de duas possibilidades a ocorrer com o significado de um termo de espécie na transição de uma teoria para outra. Hacking chamou essas possíveis condições de sobreposição [overlap] e subdivisão [subdivision] (HACKING, 1993, pp.294-5). Se um termo taxonômico que ocorre em uma teoria se sobrepor ou se subdividir com outro termo taxonômico de outra teoria, então aquele termo não pode ser traduzido nos termos da teoria em que ele é sobreposto ou subdividido, isto é, ele não pode fazer parte do novo léxico. Hacking define essas condições do seguinte modo ${ }^{46}$ :

a. Um tipo sobrepõe outro tipo científico na nova ciência. Então, pela condição 1 , o tipo da antiga ciência não pode ser um tipo na nova ciência. Assim, o nome desse tipo não pode ser traduzido em qualquer expressão na nova ciência que denota um tipo científico. [...] b. Um tipo se subdivide um tipo na nova ciência que não possui subtipos. Pela condição 2 , o tipo na nova ciência é uma infima species sem subtipos científicos, e assim o novo nome não pode ser traduzido em qualquer expressão na nova ciência que denota um tipo científico (HACKING, I., 1993, p.294-5. Tradução nossa.)

As situações $a$ e $b$ geram a impossibilidade de tradução. Se um termo de espécie é sobreposto, ele não tem mais significado no novo léxico, pois ele deixa de ser parte da taxonomia. Dando um exemplo simples e pouco realista, uma nova teoria zoológica que agrupasse patos e gansos como uma mesma espécie (digamos "Pansos") excluiria os termos "Pato" e "Gan-

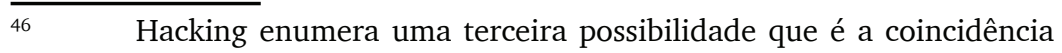
[coincidence] que não impossibilita a tradução, e portanto, não nos interessa aqui. 
so" da taxonomia, pois haveria uma sobreposição dos termos "Pato" e "Ganso" da antiga teoria sobre o termo "Pansos" da nova teoria. Podemos utilizar o mesmo exemplo, mesmo que muito simplificado, para explicar a subdivisão. Uma teoria que possui o nosso termo fictício "Panso" não pode ser traduzida em termos de uma teoria que possui os termos "pato" e "ganso" pois, justamente na taxonomia da segunda teoria, a espécie designada pelo termo "panso" se subdivide em duas espécies designadas pelos termos "pato" e "ganso", deixando "panso" de fora da taxonomia.

A condição 3 para um termo ser parte de um léxico que Hacking menciona introduz a noção de projetabilidade. Como Hacking nota, as condições 1 e 2 estão intimamente relacionadas com a possibilidade de projetar: só é possível projetar um predicado no interior de um léxico se esse predicado (1) é um termo que mantém uma relação taxonômica com outros termos desse léxico (como espécie ou subespécie) e (2) esse termo possui infima species. Como as situações (a) e (b) são violações, respectivas, das condições (1) e (2), (a) e (b) são, na verdade, situações que tornam certos predicados não projetáveis em um dado léxico. Podemos, assim, equiparar projetabilidade com tradutibilidade. Mas, nesse caso, traduzir não é apenas transpor um vocabulário em termos de outro, mas fazer com um vocabulário algo que se poderia fazer com outro (HACKING, 1993, p.297). O que emerge dessas considerações é algo mais ou menos implícito nas considerações de Kuhn, o que Hacking chamou de uma distinção entre classificar e generalizar (HACKING, 1993, pp.295-296). O ponto aqui é relativamente simples: o cientista ou aprendiz de cientista não está apenas aprendendo nomes ou rótulos para os fenômenos e objetos relevantes de sua prática ao ser exposto ostensivamente a casos paradigmáticos de solução de problemas e aplicações de conceitos, mas está aprendendo generalizações e adquirindo expectativas acerca desses fenômenos e objetos em questão. Seguindo Nelson Goodman (GOODMAN, 1983, p.87-92), Hacking chama essa capacidade de formular generalizações, ter expectativas a partir de/ou em conjunto com classificações de capacidade de projetar os predicados utilizados nessas classi- 
ficações. O que está envolvido na incomensurabilidade entre teorias defendida por Kuhn não é apenas uma diferença sobre o modo como diferentes teorias classificam objetos a partir de predicados, mas o modo como essa classificação está calcada em uma prática que torna possível projetar esses predicados.

De acordo com essa leitura, o que Kuhn defende é que há casos de impossibilidade de tradução em função do modo como léxicos de teorias são compreendidos, a saber, como conjuntos de predicados utilizados em projeções que adquirem seu significado e sua relação com o mundo através de uma prática. Dito de outra forma, o cientista não pode adotar dois léxicos que gerem projeções divergentes, pois, como vimos, a competência do cientista - que de fato é capaz de projetar os conceitos de uma teoria - não é simplesmente saber como uma teoria classifica certa classe de objetos; a capacidade de projetar um conceito envolve saber aplicá-los em situações concretas - em particular àquelas que envolvem a resolução de problemas submetidos aos conceitos da teoria (HACKING, 1994, p.213).

Foi dito anteriormente que o cientista, ao ser treinado a partir de um modelo de solução de problemas, um exemplar, adquire a capacidade de fazer projeções em conjunto com um certo modo de classificar objetos. O ponto de Kuhn, tendo em vista a leitura de Hacking, é que apenas a prática científica pode desenvolver essa habilidade. O cientista que vive um período de mudança revolucionária - que vê o abandono do antigo paradigma por um novo - não pode apenas traduzir o sistema classificatório antigo em termos do novo, pois o novo paradigma demanda uma nova prática: novos métodos de cálculo, novos instrumentos, novas técnicas de medição, novas unidades de medida e, mais importante ainda, novos exemplares e, portanto, capacidade de reconhecer conjuntos diferentes de semelhanças e diferenças.

Uma consequência disso é que há uma descontinuidade de referência de alguns termos que designam espécies naturais ao longo das revoluções científicas, dado que revoluções científicas levam redistribuições dos mesmos indivíduos em diferentes categorias taxonômicas - portanto, depende da teoria 
em que ocorrem esses termos. A natureza dessa mudança tem como principal componente ou causa dessa alteração a "alteração das características relevantes para a referência” (KUHN, 2003, p.251), que foi explicada anteriormente em termos de exemplares. De acordo com a teoria kuhniana de termos de espécie, o que torna possível realizar projeções e descrever a natureza a partir de um léxico é um treino da habilidade de reconhecer (mesmo que tacitamente) padrões de similaridade e dissimilaridade entre objetos, eventos, problemas e soluções de problemas. O fato de que tal habilidade é aprendida na prática faz com que os léxicos sirvam seu propósito de fazer projeções e descrever o mundo apenas tendo essa prática como pano de fundo. Kuhn nos diz que enunciados teóricos isolados são julgados verdadeiros ou falsos tendo como pano de fundo um léxico estabelecido (KUHN, 2003, p.120).

Se aplicarmos essa ideia a enunciados que descrevem mundos possíveis, isto é, enunciados contrafactuais, teremos uma restrição sobre os mundos possíveis que uma teoria pode ou não descrever. Um mundo possível para uma teoria é um mundo que pode ser descrito pelo léxico da teoria. Tome-se o seguinte exemplo: se uma amostra de água for aquecida a uma temperatura superior a $+/-100^{\circ} \mathrm{C}$, essa amostra de água irá evaporar". Podemos compreender esse enunciado como a descrição de um mundo possível (situação contrafactual) em que a água ferve a $+/-100^{\circ} \mathrm{C}$. Em uma situação contrafactual em que as condições normais de pressão são atendidas, o enunciado é verdadeiro; em uma situação em que as condições de pressão são anômalas, ele é falso. Há mundos possíveis em que ela é verdadeira e há mundos possíveis em que ela é falsa, mas o que dá acesso à descrição desses mundos possíveis é o léxico de uma teoria. O que Kuhn está dizendo é que uma teoria científica dá acesso ao cientista à descrição de mundos possíveis diferentes, e exclui a descrição de outros em função do modo como a teoria classifica objetos a partir de um léxico. Como ele afirma em Dubbing and Redubbing (KUHN, 1990):

A posse de um léxico, de um vocabulário estruturado, consiste no acesso a um variado conjunto de mundos possíveis que podem ser descritos pelo uso desse léxico. Léxicos diferentes 
- aqueles de diferentes culturas ou diferentes períodos históricos, por exemplo - dão acesso a conjuntos diferentes de mundos possíveis, largamente, mas nunca completamente sobrepostos [overlapping]. (KUHN, 1990, p.300. Tradução nossa.)

Com base nessa concepção dos léxicos de uma teoria e da tese de incomensurabilidade entre teorias, Kuhn mostra que a falha fundamental da ficção científica de Putnam é que ela se dá em um mundo possível que não pode ser descrito pelo léxico da química moderna, da qual os termos "H2O" e "XYZ" fazem parte. Novamente, em Dubbing and Redubbing, o ponto é colocado de modo bastante claro:

Os termos 'XYZ' e 'H20' são tomados da teoria química moderna, e essa teoria é incompatível com a existência de uma substância com praticamente as mesmas propriedades da água mas descrita com uma fórmula química elaborada. Tal substância iria, dentre outras coisas, ser muito pesada para evaporar em temperaturas terrestres normais. Sua descoberta iria apresentar problemas como a violação simultânea da segunda lei de Newton e a lei da gravitaçã̃o descrita na última seção. Isso iria, de fato, demonstrar a presença de erros fundamentais na teoria química que nos dá o significado de nomes compostos como 'H20' e a forma não abreviada de 'XYZ'. No interior do léxico da teoria química, um mundo consistindo tanto da nossa Terra e da Terra Gêmea de Putnam é lexicalmente possível, mas o enunciado composto que o descreve é necessariamente falso. Apenas com um léxico estruturado diferentemente, um moldado para descrever um tipo de mundo muito diferente, alguém poderia, sem contradição, descrever o comportamento de 'XYZ' de algum modo e, nesse caso, 'H20' poderia não mais referir ao que chamamos de 'água'. (KUHN, 1990, p.310. Tradução nossa.)

O ponto fundamental é que o cenário montado por Putnam não pode ser descrito pela melhor teoria química de que dispomos - que o mundo possível em que a Terra e a Terra Gêmea existem é um mundo possível excluído pelo léxico de nossa teoria química atual. Como diz Kuhn, os terráqueos que visitaram a Terra Gêmea, ao voltarem para a Terra, não diriam "Na Terra Gêmea, a palavra "água" significa XYZ" (PUTNAM, 1975, p.223), mas, sim, "De volta à mesa de trabalho! Há algo terrivelmente errado com a teoria química!." (KUHN, 2003, p.103). Como Wes Sharrock e Rupert Read (2002) notam cor- 
retamente, na versão Kuhniana do experimento de Putnam, o que ocorreria com a descoberta do composto XYZ da Terra Gêmea seria uma revolução científica radical na teoria química e, não, reflexões acerca do modo como a referência do termo "água" á fixada (SHARROCK \& READ, 2002, p.155); de modo que, das razões de Kuhn para afirmar a incomensurabilidade entre teorias compreendidas em termos de estruturas lexicais, o "essencialismo de Putnam" simplesmente erra o alvo como a tese Kuhniana de descontinuidade de referência (SHARROCK \& READ, 2002, p.155).

Caso as considerações de Kuhn mencionadas sejam aceitas, o fato do experimento mental de Putnam violar a taxonomia da química moderna faz com que sua conclusão sobre a continuidade de referência dos tipos naturais como "água" não se siga sem considerações adicionais, ao menos no que se refere ao experimento da Terra Gêmea e exemplos similares ${ }^{47}$. $47 \quad$ É importante notar, no entanto, que Kuhn não está argumentando que a teoria causal como um todo é falsa e completamente descartável - apenas que ela é uma teoria incompleta. A aplicação dela a nomes próprios é aceita por Kuhn de maneira não problemática (KUHN, 2003, p.251), de modo que ele está de acordo com Putnam e Kripke pelo menos no seguinte ponto: sejam lá quais forem as crenças dos cientistas sobre os objetos do mundo que eles mantiveram ao longo da história da ciência, eles estavam falando sobre os mesmos indivíduos. Ptolomeu e Copérnico discordavam sobre como classificar Júpiter, Marte, o Sol e a Terra, mas estavam classificando a mesma coisa, isto é, os mesmos indivíduos, cujos nomes designam (na maior parte dos casos) rigidamente. Este ponto merece ênfase devido à existência de leituras caricatas da tese de incomensurabilidade de acordo com as quais Kuhn defende a existência de descontinuidade de referência até mesmo com respeito a termos singulares. Kuhn sempre deixou claro que o objeto que Copérnico e Ptolomeu viam todas as manhãs ao acordarem e que chamavam pelo nome "Sol" era o mesmo objeto - e que hoje os cientistas continuam falando do mesmo objeto (KUHN, 2003, p.251). O acordo acaba quando o tratamento proposto pela teoria causal é estendido para tipos naturais sem restrição. Mas, novamente, Kuhn não pensa que a teoria causal está completamente errada. Revoluções científicas consistem, para ele, justamente no tipo de mudança que a teoria causal exclui (no caso de "água", antes da Revolução Química, o termo nem sempre referiu a tudo que sabemos (ou pensamos saber) ser $\mathrm{H} 2 \mathrm{O}$, mas apenas à água líquida - vapor e gelo excluídos, portanto). No entanto, revoluções científicas não ocorrem o tempo todo, mas são episódios intercalados por um longo tempo em que todo o léxico e, portanto, as referências dos termos de espécie que formam a taxonomia, permanecem constantes. Kuhn não afirma que termos teóricos nunca têm extensão está- 
A teoria causal não toca no problema da dependência da referência de termos isolados em relação à estrutura lexical de uma teoria, dado que Kuhn oferece argumentos (persuasivos) para estabelecer a tese de que a referência de termos científicos depende do léxico em que esses termos estão inseridos e do modo como são aprendidos. Se Kuhn está correto no que se refere ao funcionamento de termos de um léxico, pelas razões oferecidas anteriormente, então a teoria causal simplesmente não é adequada, nem enquanto uma explicação, nem enquanto uma descrição da história das revoluções científicas.

A teoria Kuhniana do aprendizado e fixação de termos teóricos é calcada na ideia de que atos únicos de ostensão não são suficientes para estabelecer a referência de termos de espécie. Segundo ele, para localizar um termo como "água" no interior de um léxico, é necessário que outros termos sejam compreendidos. Definir ostensivamente "água" apontando para um copo pode ser adequado em algumas situações, mas, no caso de "H2O", é necessário que um amplo (e complexo) vocabulário esteja à disposição do aprendiz:

O léxico requerido para rotular atributos como ser-H2O ou ser-partículas-densamente-compactadas-em-rápido-movimento- relativo é rico e sistemático. Ninguém pode usar qualquer um dos termos que ele contém sem ser capaz de usar muitos." (KUHN, 2003, p.106)

Como no caso da teoria física, não é possível ensinar termos como "massa", "força" e "aceleração" isoladamente, dado que a compreensão adequada de cada um desses termos deverá incluir todos eles. Essa é a razão apontada por Kuhn pela qual o aprendizado com os exemplares não serve para o aprendizado de termos isolados. No caso da composição química de fórmulas como $\mathrm{H} 2 \mathrm{O}$, o aprendiz deve ser capaz, por exemplo, de diferenciar essa substância de outras fórmulas químicas como

vel, apenas que nem sempre eles têm extensão estável. Além disso, é sempre importante lembrar que revoluções kuhnianas nunca são radicais a ponto de substituir todo ou mesmo a maioria do léxico que os cientistas utilizam para descrever o mundo, ou seja, mesmo nos períodos de revolução, é apenas um grupo restrito de termos que têm sua extensão alterada (do mesmo modo que é apenas um grupo restrito de termos que não pode ser traduzido). 
H2O2 (água oxigenada) a partir de padrões de similaridade e dissimilaridade relevantes para a classificação no interior da teoria química em questão. No caso de $\mathrm{H} 2 \mathrm{O}$ e $\mathrm{H} 2 \mathrm{O} 2$, essas substâncias têm estruturas químicas diferentes, mas também apresentam, por exemplo, diferentes pontos de ebulição e diferentes reações com outras substâncias - características que são relevantes para sua identificação (KUHN, 2003, pp.106-7).

O ponto aqui é que "definições ostensivas" pressupõem conhecimento acerca daquilo que está sendo definido, e, no caso de termos científicos, esse conhecimento consiste no domínio de parte de um léxico que forma uma rede de termos interconectados. E isso nos leva às razões de Kuhn para recusar a distinção entre as propriedades essenciais e acidentais de espécies. Segundo ele:

As chamadas propriedades superficiais não são menos necessárias do que suas sucessoras aparentemente essenciais. Dizer que a água é $\mathrm{H} 2 \mathrm{O}$ líquido é localizá-la no interior de um elaborado sistema lexical e teórico. Dado esse sistema - o que é preciso para o uso do rótulo -, podem-se, em princípio, predizer as propriedades superficiais da água (exatamente como se podiam predizer as de XYZ), calcular seus pontos de ebulição e congelamento, os comprimentos de onda ópticos que ela vai transmitir, e assim por diante. Se a água é H2O líquido, então essas propriedades lhe são necessárias. Se elas não fossem constatadas na prática, isso seria uma razão para duvidar de que a água realmente fosse $\mathrm{H} 2 \mathrm{O}$. (KUHN, 2003, p.107)

No léxico da química moderna, as propriedades que os defensores da teoria causal chamam de "superficiais" são parte tão fundamental do léxico da teoria quanto as fórmulas químicas, que são tratadas pelos defensores da teoria causal como "essências". Novamente apontando problemas na própria formulação do experimento de Putnam, Kuhn nota que a diferenciação entre substâncias baseada na diferença entre fórmulas químicas está intrinsecamente conectada com a explicação das diferenças "superficiais" entre essas substâncias. Dizer que o fato da composição da água ser H2O está apenas acidentalmente conectado com o fato de que água (H2O) é o que cai das nuvens ou mata a sede dos humanos ou tem uma determinada 
cor etc, é, segundo Kuhn, absurdo, dada a estrutura lexical da teoria química e os fenômenos que ela pretende explicar.

Em suma, as razões de Kuhn para sustentar a tese de incomensurabilidade não são comprometidas pelos argumentos a favor da teoria causal. Kuhn compreende teorias como léxicos que classificam objetos e eventos, a formar um sistema de classificação de categorias taxonômicas que, após períodos de revoluções científicas, podem sofrer alterações em suas estruturas. Essa espécie de mudança traz consigo a alteração nas projeções que as teorias permitem e a impossibilidade de uma tradução sem perda ou mudança de significado e referência (extensão) de alguns termos que formam o léxico de teorias incomensuráveis.

Argumentamos que a principal razão de Kuhn para sustentar a incomensurabilidade entre teorias é que termos científicos são aprendidos através de treinamento dos cientistas a partir dos exemplares, com os quais os cientistas adquirem a capacidade de reconhecer padrões de similaridade e dissimilaridade entre objetos e fenômenos. Essa habilidade de reconhecer os conjuntos de similaridade e dissimilaridade é a capacidade de usar os termos científicos que compõem o léxico da teoria, e a incomensurabilidade surge em razão da mudança no conjunto de relações de similaridade e dissimilaridade cuja causa é a mudança de paradigma. A estratégia argumentativa kuhniana é de questionar a coerência do argumento da Terra Gêmea de Putnam e a plausibilidade da aplicação da teoria causal a termos científicos.

A posição kuhniana é que os léxicos teóricos são adquiridos através do treino com os exemplares, o que faz com que termos não possam ser aprendidos isolados ou independentemente de um vocabulário pré-existente - o que compromete a possibilidade de um batismo (dubbing) independente de qualquer teoria ou léxico. Desse modo, predicados utilizados para descrever as propriedades que Putnam chama de acidentais são tão essenciais quanto àqueles que ele toma como essenciais, de modo que a distinção, tal como apresentada por Putnam, não tem lugar em um relato adequado da prática científica. Nossa 
conclusão é que, se a interpretação da tese de incomensurabilidade de Kuhn aqui formulada é adequada, então ela não é refutada pela teoria causal sem considerações adicionais.

\section{Referências:}

FREGE, Gottlob. On Sense and Reference. Trad. Max Black e Peter Geach. The Philosophical Review, v.57, n.3, (Maio) 1948, pp.209-230. GOODMAN, Nelson. Facts, fiction and forecast. Cambridge: Harvard University Press, 1983.

HACKING, Ian. Working in a new world: the taxonomic solution. In: HORWICH, Paul. (ed.). World changes: Thomas Kuhn and the nature of science. Cambridge: MIT Press, 1983, pp.275-310.

HACKING, Ian. Representar e Intervir: Tópicos Introdutórios à Filosofia das Ciências Naturais. Trad. Pedro Rocha de Oliveira. Rio de Janeiro: EDUERJ, 2012.

KUHN, Thomas. Dubbing and redubbing: The vulnerability of rigid designation. In: SAVAGE, Wade, CONANT, James \& HAUGELAND, John (eds.). Minnesota Studies in the Philosophy of Science. University of Minnesota Press, 1990, pp. 58-89.

KUHN, Thomas. O Caminho Desde a Estrutura. Trad. César Augusto Mortari. São Paulo: Editora UNESP, 2003.

KUHN, Thomas. The Structure of Scientific Revolutions 4th Edition. Chicago: Chicago University Press, 2012.

KRIPKE, Saul. Naming and necessity. Cambridge: Harvard University Press, 1980.

PUTNAM, Hilary. Mind, language and reality: philosophical papers vol.2. Cambridge: Cambridge University Press, 1975.

SHARROCK, Wes e READ, Rupert. Thomas Kuhn's Misunderstood Relation to Kripke- Putnam Essentialism. Journal for General Philosophy of Science, v.33, n.1, 2002, pp.151-158. 